\title{
IMPLEMENTASI KURIKULUM UNTUK MENINGKATKAN MUTU LULUSAN DI PESANTREN AR-RAUDHATUL HASANAH MEDAN
}

\author{
Nurmayani \\ Dosen Jurusan PPSD Prodi PGSD FIP UNIMED \\ surel: nur.mayani21@yahoo.co.id
}

\begin{abstract}
Abstrak
Penelitian ini bertujuan untuk mengetahui Implementasi Kurikulum Pesantren Ar- Raudhatul Hasanah dalam meningkatkan mutu lulusan, untuk mengetahui strategi Pengembangan Profesional Ustadz dalam meningkatkan mutu lulusan, untuk mengetahui masalah- masalah yang dihadapi Pesantren dalam mewujudkan kurikulumnya dan bagaimana solusinya. Penelitian ini menggunakan metode kualitatif, lokasinya di Pesantren Raudhatul Hasanah. Teknik pengumpulan data yang digunakan yaitu: Observasi, wawancara, Studi dokumentasi. Pengelolaan data terdiri dari: Reduksi data, Display data / penyajian data, Analisis data, meningkatkan keabsahan hasil. Hasil penelitian sebagai berikut: kurikulum yang dilaksanakan pada Pesantren Ar- Raudatul Hasanah adalah perpaduan antara kurikulum Pesantren Gontor dengan penyesuaian dan pengembangan juga Kurikulum Tingkat Satuan Pendidikan (KTSP). Setiap dua minggu sekali supervisor melakukan sharing terhadap para Ustadz dan ustadzah dalam pembuatan Program Tahunan, Program semester, Silabus, RPP dan melakukan kerjasama dengan pengawas pesantren setempat.
\end{abstract}

Kata kunci: Implementasi Kurikulum Dalam Meningkatkan Mutu Lulusan

\section{PENDAHULUAN}

Banyak orang menganggap bahwa kurikulum hanya berkaitan dengan bahan ajar atau buku-buku pelajaran. Sebenarnya kurikulum tidak hanya sekedar mempelajari mata pelajaran tetapi lebih mengembangkan pikiran, menambah wawasan, serta mengembangkan pengetahuan yang dimilikinya. Ia lebih mempersiapkan peserta didik atau subjek belajar yang baik dalam memecahkan masalah individualnya maupun masalah yang dihadapi oleh lingkungan. Dalam perjalanannya dunia pendidikan Indonesia telah menerapkan beberapa Kurikulum, yaitu Kurikulum 1947 atau disebut
Rentjana Pelajaran 1947, Kurikulum 1952 - Rentjana Pelajaran Terurai 1952, Kurikulum 1964 - Rentjana Pendidikan 1964, Kurikulum 1968, Kurikulum 1975, Kurikulum 1984, Kurikulum 1994 dan Suplemen Kurikulum 1999, Tahun 2004 Kurikulum Berbasis Kompetensi, Tahun 2006 - Kurikulum Tingkat Satuan Pendidikan. Kurikulum Tingkat Satuan Pendidkan (KTSP) yang dikeluarkan pemerintah melalu Permen Diknas Nomor 22 tentang Standar Isi, Permen Nomor 23 tentang Standar Kompetensi Lulusan, dan Permen Nomor 24 tentang pelaksanaan ke dua Permen tersebut. 
KTSP disusun oleh masingmasing sekolah dengan mengacu pada Standar Kompetensi Lulusan (SKL) dan Standar Isi (SI) untuk jenjang pendidikan dasar dan menengah. Penyerahan pengembangan KTSP pada tiap sekolah dengan mengacu pada kedua standar di atas bertujuan agar kurikulum tersebut dapat disesuaikan dengan karakter dan tingkat kemampuan sekolah masing-masing. Pedoman penilaian dan penentuan kelulusan peserta didik mengacu pada SKL yang meliputi kompetensi untuk kelompok mata pelajaran atau kompetensi untuk seluruh mata pelajaran yang dinilai berdasarkan kualifikasi kemampuan mecakup sikap, pengetahuan dan keterampilan. Standar ISI merupakan ruang lingkup materi dan tingkat kompetensi yang dituangkan dalam persyaratan kompetensi tamatan, kompetensi bahan kajian kompetensi mata pelajaran, dan silabus pembelajaran yang harus dipenuhi peserta didik pada jenjang dan jenis pendidikan tertentu. Standar ISI ini sendiri merupakan pedoman untuk pengembangan KTSP

Kurikulum memiliki dua fungsi diantaranya, yaitu kurikulum sebagai dokumen dan kurikulum sebagai implmentasi. Kurikulum sebagai dokumen berfungsi sebagai pedoman bagi pendidik dan kurikulum sebagai implementasi adalah realisasi dari pedoman dalam bentuk kegiatan pembelajaran. Sejak berdirinya Pesantren Ar-Raudhatul Hasanah telah mengadopsi kurikulum dari Pesantren Gontor pada mata pelajaran agama dan mata pelajaran bahasa arab dengan beberapa penyesuaian dan pengembangan, namun dengan perkembangan kurikulum di Indonesia, Pesantren ini juga menggunakan kurikulum KTSP seperti mata pelajaran Agama dan Akhlak Mulia (Qur'an Hadits, Aqidah Akhlak, Fiqih, Sejarah Kebudayaan Islam), Pendidikan Kewarganegaraan, Bahasa (B. Indonesia, B. Arab, B. Inggris), Matematika, Kesenian, Pendidikan Jasmani, Ilmu Pengetahuan Sosial (Sejarah, Geografi, Ekonomi, Sosiologi), Ilmu Pengetahuan Sosial (Fisika, Kimia, Biologi), Teknologi Informasi dan Komunikasi, Muatan lokal (Kepesantrenan) dan Pengembangan diri yang menggunakan kurikulum tingkat santuan pendidikan atau disingkat dengan KTSP.

Program pendidikan jalur sekolah di Pesantren Ar-Raudhatul Hasanah ada dua yaitu:

a. KMI (Kulliyatul Mu'alimin AlIslamiyah) adalah sistem pendidikan formal yang merupakan lembaga pendidikan lanjutan tingkat pertama dan menengah yang berbasis dan berbentuk Pesantren, dengan masa studi enam tahun bagi tamatan SD/MI (untuk program reguler), dan empat tahun bagi tamatan SLTP/MTS (untuk program intensif) menggunakan kurikulum pondok moderen 
Gontor dengan beberapa penyesuaian dan pengembangan.

b. Madrasah Tsanawiyah dan Aliyah yang menggunakan kuriklum Departemen agama. Untuk jenjang Madrasah Aliyah membuka dua jurusan yaitu IPA dan IPS.

Proses pendidikan di KMI berlangsung secara terencana dan terus-menerus selama 24 jam dengan penekanan khusus pada upaya tafaqquh fiddiin, yaitu; dengan memberikan bekal-bekal dasar keulamaan, kecendiakawanan, kepemimpinan dan keguruanan dalam rangka mencetak kader-kader Mundzirul-qaum (pemimpin umat). Semenjak berdirinya Pesantren Ar-Raudhatul Hasanah telah menerapkan penggunaan bahasa Arab dan Inggris sebagai bahasa pengantar dalam pembelajaran dan dalam kehidupan sehari-hari di Pesantren. Untuk itu bagi yang tidak patuh akan mendapat hukuman yang mendidik seperti menghapal kosa kata baru atau dengan menterjemahkan kalimat kedalam bahasa Arab dan Inggris. Dan santri yang berprestasi

\section{METODOLOGI PENELITIAN}

Penelitian ini merupakan kajian kualitatif, yaitu pendekatan yang temuan-temuan penelitiannya tidak diperoleh melalui prosedur statistik atau komputer, prosedur ini menghasilkan temuan-temuan yang diperoleh dari data-data yang dikumpulkan dengan wawancara, mendapatkan beasiswa dari Pesantren dan santri yang kurang mampu akan mendapatkan dana BOS dari pemerintah.

Bagi Ustadz-ustadzah setiap dua tahun sekali diundi Pesantren untuk di daftarkan naik haji gratis, begitu juga dengan pekerja-pekerja yang bekerja di bidang lain. Setiap dua minggu sekali Ustadz-ustadzah melakukan sharing dalam membuat RPP dan juga mengevaluasi pembelajaran yang telah dilaksanakan. Tenaga pendidiknya berasal dari pendidikan S1 dan S2 baik dari Sumatera, Jawa maupun tamatan dari timur tengah. Guru-guru dilatih untuk mengikuti pelatihan bahasa Inggris, dalam rangka meningkatkan mutu guru, dengan pendekatan Neoro Linguistic Programming, dan Ustadz-Ustadzah yang sudah lulus sertifikasi mendapatkan pelatihan pembuatan program tahunan, program semester dan Rancangan Pelaksanaan Pembelajaran yang bekerja sama dengan pengawas sekolah. Hal ini diadakan untuk peningkatan kualitas dan tekhnik mengajar Ustadustadzah.

\section{Jenis Penelititan}

observasi, dan studi dokumentasi. Dari kajian tentang defenisi di atas dapat disintesiskan bahwa penelitian yang penulis lakukan pada pesantrten Ar-Raudhatul Hasanah adalah metode kualitatif yang berupaya untuk memahami dan mendalami secara holistik tentang Implementasi 
Kurikulum untuk meningkatkan mutu lulusan siswa yang tidak menggunakan prosedur analisis statistik atau cara kuantifikasi lainnya dan dengan cara deskriptif dalam bentuk-kata-kata dan bahasa pada suatu konteks khusus yang alamiah dan dengan memanfaatkan berbagai metode penelitian yaitu observasi, wawancara dan pemanfaatan dokumen.

\section{Lokasi dan Waktu Penelitian}

Penelitian ini dilaksanakan di Pesantren Ar-Raudhatul Hasanah yang dimulai pada bulan Januari 2013 sampai bulan januari 2014, yang dijadikan responden dalam penelitian ini yaitu : Direktur ArRaudhatul Hasanah, Ketua Harian Badan Wakaf Pondok Pesantren ArRaudhatul Hasanah, Kepala sekolah, Ustadz dan Ustadzah, Pegawai Tata Usaha, Unsur komite, Santriwan/wati Bidang Pendidikan, Bidang Pengasuhan, Bidang Kesejahteraan, Bidang Penelitian dan Pengembangan, Bidang Usaha Milik Pesantren, dan yang ada kaitannya dengan kurikulum Ar-Raudhatul Hasanah.

\section{Tekhnik Pengumpulan Data}

a. Observasi

$$
\text { Penulis menggunakan }
$$

observasi adalah suatu teknik pengumpulan data dengan melakukan pengamatan langsung kegiatan pembelajaran di dalam kelas, maupun diluar kelas terhadap subjek (partner penelitian) dimana sehari-hari mereka berada dan bisa melakukan aktifitasnya guna melihat dan mengamati proses kegiatan Pendidikan di Pondok Pesantren ArRaudhatul Hasanah, yang berkaitan dengan Implementasi kurikulum untuk meningkatkan mutu lulusan.

b. Wawancara

Wawancara yang penulis lakukan adalah untuk memperoleh data yang rasional, maka observasi perlu dikuatkan dengan wawancara. Wawancara merupakan teknik pengumpulan data dengan melakukan dialog langsung dengan sumber data yaitu Direktur ArRaudhatul hasanah, Ketua Harian Badan Wakaf Pondok Pesantren ArRaudhatul Hasanah Kepala-kepala Sekolah, Komite Madrasah dan Santriwan/wati dilakukan secara tak berstruktur, dimana responden mendapatkan kebebasan dan kesempatan untuk memngeluarkan pikiran, pandangan dan perasaan secara natural. Dalam proses wawancara ini di dokumentasikan dalam bentuk catatan tertulis dan audio visual, hal ini dilakukan untuk meningkatkan kebernilaian dari data yang diperoleh.

\section{c. Studi Dokumentasi}

Dokumen merupakan catatan peristiwa yang sudah berlalu. Dokumen bisa berbentuk tulisan, gambar, atau karya-karya monumental dari seseorang. Dokumen yang berbentuk tulisan misalnya catatan harian, sejarah kehidupan (life histories), ceritera, biografi, peraturan, kebijakan. Dokumen yang berbentuk gambar, 
misalnya foto, gambar hidup, sketsa dan lain-lain. Dokumen yang berbentuk karya misalnya karya seni, yang dapat berupa gambar, patung, flim, dan lain-lain. Studi dokumen merupakan pelengkap dari penggunaan dari metode observasi dan wawancara dalam penelitian kualitatif.

Dalam studi dokumentasi ini, penulis mendapatkan foto-foto kegiatan santri, baik di dalam maupun diluar negeri, begitu juga kunjungan-kunjungan dari pejabat dalam negeri maupun luar negeri, yang dapat mendukung proses penelitian.

\section{Pengolahan Data}

a. Reduksi Data

Dalam reduksi data ini, tentu saja penulis mengadakan penelitian berulang-ulang, dimana semakin lama peneliti di lapangan, maka hasil penelitian pun semakin banyak, oleh sebab itu dibutuhkan analisis data dengan cara mereduksi data, yang berarti merangkum, memilih hal-hal yang pokok, memfokuskan hal-hal yang penting dicari tema dan polanya serta membuang yang tidak perlu, sehingga data yang diperoleh memberikan gambaran yang jelas tentang Pesantren Ar-Raudhatul Hasanah.

\section{b. Display Data/Penyajian Data}

Dengan mendisplaykan data yang peneliti peroleh dari lapangan, maka akan memudahkan untuk memahami apa yang terjadi, merencanakan kerja selanjutnya berdasarkan apa yang telah dipahami tersebut. Data yang penulis peroleh dikategorisasikan menurut pokok permasalahan dan dibuat dalam bentuk matriks sehingga memudahkan peneliti untuk melihat pola-pola hubungan satu data dengan data lain.

\section{c. Analisis data}

Dalam melakukan analisi data, sebelum peneliti memasuki Pesantren Ar-Raudhatul Hasanah, selama di Pesantren, dan setelah selesai dari Pesantren.dan pada saat wawancara peneliti sudah melakukan analisis data terhadap jawaban yang diwawancarai. Bila jawaban yang di wawancarai setelah di analisis terasa belum memuaskan maka peneliti melakukan pertanyaan lagi sampai tahap tertentu diperoleh data yang dianggap kredibel.

\section{d. Mengambil Kesimpulan Dan Verifikasi}

Setelah peneliti menganggap penelitian itu sudah selesai dan datadata yang diperolehpun telah sesuai dengan judul peneliti maka peneliti pun mengambil kesimpulan dengan cara melakukan verifikasi atas datadata yang sudah diproses atau ditransper kedalam bentuk-bentuk yang sesuai dengan pola pemecahan permasalahan yang dilakukan.

\section{Meningkatkan Keabsahan Hasil}

Uji keabsahan data dalam penelitian kualitatif meliputi uji, credibility (validitas internal), transferability (validitas external), 
dependability (reliabilitas), dan confirmability (obyektivitas).

a. Uji Kredibilitas (Validitas internal)

adalah tingkatan dimana hasil-hasil penelitian dapat dipercaya kebenarannya. Validitas internal merupakan hal yang esensial yang harus dipenuhi jika peneliti menginginkan hasil studinya bermakna. Keabsahan atas hasil-hasil penelitian dilakukan dengan perpanjangan pengamatan, peningkatan ketekunan, triangulasi, diskusi dengan temen sejawat, analisis kasus negatif, dan memberchek.

\section{b. Pengujian Transferability (validitas eksternal) \\ Ialah tingkatan dimana hasil-} hasil penelitian dapat digeneralisasi pada populasi, latar dan hal-hal lainnya dalam kondisi yang mirip. Supaya orang lain dapat memahami hasil penelitian kualitatif, maka peneliti dalam membuat laporannya harus memberikan uraian yang rinci, jelas, sistematis dan dapat dipercaya. Dengan demikian maka pembaca menjadi jelas atas hasil penelitian tersebut, sehingga dapat memutuskan atau tidak, untuk mengaplikasikan hasil penelitian tersebut di tempat lain

Dengan melakukan penelitian yang benar, jelas, dan rinci tentang kurikulum Pesantren maka penelitian ini dapat di transfer atau diaplikasikan di tempat lain. c. Pengujian Depenability

Dalam penelitian kualitatif, uji depenability dilakukan dengan melakukan audit terhadap keseluruhan proses penelitian.

Dalam melakukan uji dependability tentunya peneliti langsung ke objek penelitian yaitu ke Pesantren Ar-Radhatul Hasanah untuk mendapatkan data yang jelas, rinci dan benar serta dilakukan dengan berulang-ulang sehingga penelitian ini dianggap valid.

\section{d. Pengujian Konfirmability}

Dalam penelitian kualitatif, uji konfirmability mirip dengan uji depenability, sehingga pengujiannya dapat dilakukan secara bersamaan. Menguji konfirmability berarti menguji hasil penelitian, dikaitkan dengan proses yang dilakukan. Bila hasil penelitian merupakan fungsi dari proses penelitian yang dilakukan, maka penelitian tersebuut telah memenuhi standar konfirmability. Dalam penelitian, jangan sampai proses tidak ada, tetapi hasilnya ada. Uji konfirmability ini juga hampir sama dengan uji dependability dimana proses penelitian harus ada sehingga hasilnya bisa dianggap kredibel.

\section{Narasi Hasil Analisis}

Pembahasan dalam penelitian kualitatif menyajikan informasi dalam bentuk teks tertulis atau bentuk-bentuk gambar mati atau hidup seperti photo dan vidio dan lain-lain. Dalam menarasikan data 
kualitatif ada beberapa hal yang perlu diperhatikan yaitu;

a. Tentukan bentuk (form) yang akan digunakan dalam menarasikan data.

b. Hubungkan bagaimana hasil yang berbentuk narasi itu menunjukkan tipe/bentuk keluaran yang sudah didesain sebelumnya

\section{HASIL PENELITIAN DAN PEMBAHASAN}

A. Imlplementasi

Kurikulum

Pesantren

Ar-Raudhatul

Hasanah

Pesantren ini pada awal berdirinya mengadopsi kurikulum dari Pesantren gontor, yaitu tidak memisahkan pengetahuan agama dan pengetahuan umum. Karena hal ini sesuai dengan pendapat Imam Zarkasyi pendiri Pondok Pesantren Gontor, yang mengatakan bahwa Islam tidak memisahkan pengetahuan agama dan umum, sebenarnya pengetahuan umum adalah bagian dari ilmu pengetahuan agama, dan sama pentingnya namun dengan perkembangan kurikulum di Indonesia, Pesantren ini juga menggunakan kurikulum KTSP yang sesuai dengan kurikulum Pemerintah, seperti mata pelajaran Agama dan Akhlak Mulia (Qur'an Hadits, Aqidah Akhlak, Fiqih, Sejarah Kebudayaan Islam), Pendidikan Kewarganegaraan, Bahasa (B. Indonesia, B. Arab, B. Inggris), Matematika, Kesenian, Pendidikan Jasmani, Ilmu Pengetahuan Sosial (Sejarah, Geografi, Ekonomi,
Sosiologi), Ilmu Pengetahuan Sosial (Fisika, Kimia, Biologi), Teknologi Informasi dan Komunikasi, Muatan lokal (Kepesantrenan) dan Pengembangan diri yang menggunakan Kurikulum Tingkat Satuan Pendidikan atau disingkat dengan KTSP.

Kegiatan-kegiatan yang terdapat dalam kurikulum ArRaudhatul Hasanah terbagi kepada empat bagian, yaitu: Intra kurikuler, ko kurikuler, ekstra kurikuler dan hidden kurikulum.

a. Intra kurikuler yaitu : Insya', Muthola'ah, Tamrinul Lughoh, Tafsir, Hadits, Mustholahul hadits, Nahwu, Shorf, Muqaranatul adyan, Tauhid, Mantiq, Fiqh, Ushul fiqh, Faraidh, Mahfuzat, Balaghah, Kaligrafi/ khot, Imla', Reading, Grammar, Tarbiyah, Tajwidul Quran, Tarikh Islam, Tarjamah, Hisab, Bhs. Indonesia, Matematika, Ekonomi, Akutansi, Fisika, Biologi, Kimia, Sosiologi/Antropologi, Geografi, Tata Negara.

b. Ko kurikuler yaitu: Khutbah jum'at bagi pria., Amaliah tadarus kelas V KMI, Khutbah Wada', Khataman dan Yudisium kelas VI., Pengkajian kitab kuning, Praktek mengajar, Pelaksanaan manasik haji, Pengurusan jenazah. Selain kegiatan tersebut diatas masih ada kegiatan lainnya yaitu: Kegiatan Harian: Setoran Ziadah, Setoran Muraja'ah.,Tadarus 
Qur'an, Imam Shalat

Berjama'ah.

Kegiatan Mingguan: Tahsin Al-

Qur'an, Qiyamul Lail

Berjama'ah.

Kegiatan Bulanan: Evaluasi

Bulanan, kegiatan ini berbentuk

tes kualitas hapalan santri,

Ceramah dan Kajian

Keagamaan.

Kegiatan Tahunan: Al-Qur'an

Memorizing Kontes (AMC),

Kegiatan perlombaan menghapal

Al-Qur'an, antara lain: hafalan juz 'amma, 1 juz, 2 juz dan 3

juz. Target Jam'iyyatul Huffas

yakni 3 juz persemester, atau 6 juz pertahun, 30 juz dalam jangka 5 tahun., Pelatihan Tahfiz

c. Ekstra Kurikuler yaitu: Membentuk Organisasi Pelajar Ar-Raudhatul Hasanah (OPRH), Membentuk Gugus Depan, Membentuk Marching Band Competition, Pelatihan LKBB, Kursus Komputer, Kursus Pers Dan Jurnalitik, Membuat Majalah Dinding, Menerbitkan Buku Tauhid, Pelatihan Penulisan Buku, Kemah Buku Dan Reading Habit, Membuat Buletin Jumat/Ramadhan, Mengadakan Lomba Karya Ilmiah Dan Resensi Buku, Perlombaan Pidato Tiga Bahasa, Mengadakan Gebyar Olimpiade, Membuat Klub Drama, Membuat Klub Tarian, Membuat Klub Silat. d. Hidden

Kurikulum (Kurikulum Tersembunyi).

Metode-Metode Yang

Dilaksanakan Di Pesantren ArRaudhatul Hasanah yaitu : Metode Klasikal, Metode Hafalan, Metode Wetonan Metode Sorogan, Metode Tanya jawab, Metode Ceramah, Metode Diskusi.

\section{Strategi Pengembangan Profesional ustadz-ustadzah Dalam Meningkatkan Mutu Lulusan}

Ustadz dan Ustadzah yang mengajar di Pesantren ini adalah alumni dari KMI Ar-Raudhatul Hasanah, alumni Pondok Modern Darusssalam Gontor dan alumni dari berbagai Perguruan Tinggi baik di dalam maupun di Luar Negeri.

a. Adapun tugas Ustadz supervisor ini yaitu setiap 2 minggu 1 kali mereka mengevaluasi pelajaran yang telah diberikan Ustadz kepada anak didik untuk mengetahui apakah terdapat perbedaan antara kemampuan, keterampilan, kepuasan, dan disiplin kerja Ustadz sebelum dan sesudah mendapatkan supervisi. Perubahan dan atau peningkatan demikian perlu diketahui, agar dapat diketahui juga tingkat keberhasilan supervisi. Kemudian selain itu supervisor juga melakukan sharing terhadap Ustadz dan Ustadzah yang di supervisi 
dalam pembuatan Program tahunan /Program semester, Silabus, RPP dan melakukan kerja sama dengan pengawas sekolah setempat. Dalam meningkatkan kinerja ustadz, ustadzah dan staf administrasi setiap dua tahun sekali diundi dan pemenangnya didaftarkan untuk melaksanakan ibadah haji gratis.

b. Dalam meningkatkan kinerja ustadz, ustadzah, dan staf administrasi terus dilatih dalam Bahasa Inggris, dengan pendekatan Neoro Lenguistic Programming.

c. Bagi-ustadz dan ustadzah yang berprestasi diberi peluang untuk belajar S2 dan S,3 baik dalam maupun luar negeri, dan biayanya di tanggung oleh pesantren.

Struktur dan Muatan Kurikulum Pesantren Ar-Raudhatul Hasanah KELAS X

\begin{tabular}{|c|c|c|c|}
\hline \multirow{2}{*}{$\begin{array}{l}\mathrm{NO} \\
\mathrm{A.}\end{array}$} & \multirow{2}{*}{$\begin{array}{l}\text { KOMPONEN } \\
\text { MATA PELAJARAN }\end{array}$} & \multicolumn{2}{|c|}{ KELAS DAN ALOKASI WAKTU } \\
\hline & & Semester I & Semester II \\
\hline \multirow[t]{5}{*}{ I } & \multicolumn{3}{|l|}{ Pelajaran Agama dan Akhlak Mulia } \\
\hline & 1. Qur'an Hadits & 2 & 2 \\
\hline & 2. Aqidah Akhlak & 1 & 1 \\
\hline & 3. Fiqih & 2 & 2 \\
\hline & 4. Sejarah Kebudayaan Islam & 1 & 1 \\
\hline II & Pendidikan Kewarganegaraan & 2 & 2 \\
\hline \multirow[t]{4}{*}{ III } & \multicolumn{3}{|l|}{ Bahasa } \\
\hline & 1. B. Indonesia & 4 & 4 \\
\hline & 2. B. Arab & 2 & 2 \\
\hline & 3. B. Inggris & 4 & 4 \\
\hline IV & Matematika & 4 & 4 \\
\hline V & Kesenian & 2 & 2 \\
\hline VI & Pendidikan JasmaniD & 2 & 2 \\
\hline \multirow[t]{5}{*}{ VII } & \multicolumn{3}{|l|}{ Ilmu Pengetahuan Sosial } \\
\hline & 1. Sejarah & 2 & 2 \\
\hline & 2. Geografi & 1 & 1 \\
\hline & 3. Ekonomi & 2 & 2 \\
\hline & 4. Sosiologi & 2 & 2 \\
\hline \multirow[t]{4}{*}{ VIII } & \multicolumn{3}{|l|}{ Ilmu Pengetahuan Alam } \\
\hline & 1. Fisika & 4 & 4 \\
\hline & 2. Kimia & 3 & 3 \\
\hline & 3. Biologi & 3 & 3 \\
\hline IX & Teknologi Informasi dan Komunikasi & 2 & 2 \\
\hline \multirow[t]{2}{*}{ B } & \multicolumn{3}{|l|}{ Muatan Lokal } \\
\hline & Kepesantrenan & 2 & 2 \\
\hline $\mathrm{C}$ & Pengembangan Diri & 2 & 2 \\
\hline \multicolumn{2}{|c|}{ Jumlah } & 47 & 47 \\
\hline
\end{tabular}


Hubungan

Implementasi

Kurikulum Dengan Mutu Lulusan

Sebagaimana

telah

dipaparkan pada bab 1 bahwa

kurikulum itu bukan hanya membicarakan tentang bahan ajar, tetapi juga rencana pengajaran, pengalaman belajar, konsep untuk merubah pola pikir siswa dan guru, dan dapat mengembangkan pikiran, manambah wawasan, serta dapat memecahkan masalah pribadi maupun lingkungan disekitarnya.

Disamping itu faktor-faktor yang mempengaruhi mutu lulusan yaitu: faktor anak didik, tenaga pendidik, tujuan pendidikan, materi dan media pendidikan, sarana dan prasarana, metode pembelajaran dan kurikulum. Dengan demikian dapat dikatakan bahwa implementasi kurikulum sangat berkaitan dengan mutu lulusan.. Berdasarkan wawancara yang penulis lakukan kepada salah seorang Ustadz supervisor Ar-Raudhatul Hasanah, alumni pesantren banyak yang lulus pada berbagai perguruan tinggi.

\section{Masalah-Masalah Yang Dihadapi Pesantren Dan Solusinya}

Proses pendidikan di pesantren ar-raudhatul hasanah berlangsung secara terus menerus selama 24 jam dengan penekanan khusus pada upaya tafaquh fiddin, yaitu dengan memberikan dasardasar keulamaan, kecendiakawanan, kepemimpinan dan keguruan dalam rangka mencetak kader-kader munzirul qaum. Namun dalam kehidupan pesantren ada saja masalah-masalah yang terjadi. Masalah-masalahnya antara lain yaitu: Terbatasnya ruang komputer dan hanya 60 set komputer yang dimiliki pesantren, sehingga kelas VII dan kelas VIII belum diajarkan komputer, setelah kelas IX barulah diajarkan komputer itupun hanya teori saja, dan setelah kelas X sampai kelas XII mulai diajarkan dasar-dasar komputer. Dengan melakukan kerjasama dengan waspada akhirnya santri kelas Xkelas XII sudah mampu membuat artikel, majalah. Latihan ini dilaksanakan dalam waktu 3 kali seminggu sampai mereka mahir. Dan pada tahun 2015 mulai dibangun ruang komputer dan penambahan komputer. Begitu juga laboratorium ( Bahasa, Fisika, Kimia, Biologi ), sangat terbatas sehingga yang bisa belajar di laboratorium Bahasa, hanya kelas X- kelas XII yang bisa belajar di laboratorium Kimia kelas X-kelas XII, dan yang belajar di laboratorium Biologi Dan Fisika mulai kelas VII- kelas IX. Dan tahun 2015 ini mulai dibangun lagi laboratorium. Kemudian pelajaran Matematika, Fisika, Kimia, diajarkan 3 jam pelajaran dalam seminggu. Solusinya santri kelas IX dan kelas XII yang akan mengikuti UN diadakan bimbingan belajar dengan melakukan kerjasama dengan bimbingan belajar di luar pesantren. 
SIMPULAN DAN SARAN

\section{Simpulan}

Dari hasil penelitian yang penulis lakukan pada Pesantren ArRaudhatul Hasanah maka dapat diambil kesimpulan sebagai berikut:

a. Kurikulum yang dilaksanakan pada Pesantren Ar-Raudhatul Hasanah adalah perpaduan antara Kurikulum Pesantren Gontor dengan penyesuaian dan pengembangan juga Kurikulum Tingkat Satuan Pendidikan.

b. Rencana strategi pengembangan profesional Ustadz dalam meningkatkan mutu lulusan pada Pesantren Ar-Raudhatul Hasanah antara lain yaitu:

(a). Pihak pesanteren mengangkat supervisor yang bertugas untuk mengevaluasi pelajaran yang telah diberikan para ustadz untuk mengetahui apakah terdapat perbedaan antara kemampuan, keterampilan, kepuasan dan disiplin kerja sebelum dan sesudah mendapatkan supervisi.

(b). Setiap dua minggu sekali supervisor melakukan sharing terhadap para Ustadz dan ustadzah dalam pembuatan Program tahunan, Program semester, Silabus, RPP dan melakukan kerja sama dengan pengawas sekolah setempat.

(c). Dalam meningkatkan kinerja ustadz, ustadzah dan staf administrasi setiap dua tahun sekali diundi dan pemenangnya didaftarkan untuk melaksanakan ibadah haji gratis.

(d). Dalam meningkatkan kinerja ustadz, ustadzah, dan staf administrasi terus dilatih dalam Bahasa Inggris, dengan pendekatan Neoro Lenguistic Programming.

(e). Bagi-ustadz dan ustadzah yang berprestasi diberi peluang untuk belajar S2 dan S,3 baik dalam maupun luar negeri, dan biayanya di tanggung oleh pesantren.

c. Masalah-masalah yang dihadapi Pesantren Ar-Raudhatul Hasanah dalam mewujudkan kurikulum dan solusinya yaitu: terbatasnya ruang komputer dan hanya 60 set komputer yang dimiliki pesantren, sehingga kelas VII dan kelas VIII belum diajarkan komputer, setelah kelas IX barulah diajarkan komputer itupun hanya teori saja, dan setelah kelas X sampai kelas XII mulai diajarkan dasardasar komputer. Dengan melakukan kerjasama dengan waspada akhirnya santri kelas X- kelas XII sudah mampu membuat artikel, majalah. Latihan ini dilaksanakan dalam waktu 3 kali seminggu sampai mereka mahir. Dan pada tahun 2015 mulai dibangun ruang komputer dan penambahan komputer. Begitu juga laboratorium ( Bahasa, Fisika, Kimia, Biologi ), sangat terbatas sehingga yang bisa 
belajar di laboratorium Bahasa, hanya kelas X-kelas XII yang bisa belajar di laboratorium Kimia kelas X-kelas XII, dan yang belajar di laboratorium Biologi Dan Fisika mulai kelas VII- kelas IX. Dan tahun 2015 ini mulai dibangun lagi laboratorium. Kemudian pelajaran Matematika, Fisika, Kimia, diajarkan 3 jam pelajaran dalam seminggu. Solusinya santri kelas IX dan kelas XII yang akan mengikuti UN diadakan bimbingan belajar dengan melakukan kerjasama dengan bimbingan belajar di luar pesantren.

\section{Saran}

Untuk lebih meningkatkan mutu lulusan pada Pesantren Ar-Raudhatul Hasanah diharapkan:

A. Kepada Direktur Pesantren ArRaudhatul Hasanah agar lebih meningkatkan kualitas ustadz dan ustadzah yaitu:

a) mengadakan pelatihanpelatihan, seminarseminar yang sesuai dengan bidang studi yang diajarkan paling sedikit satu bulan sekali.

b) Bagi Ustadz-ustadzah yang berprestasi agar di beri peluang lagi untuk belajar S2 Dan S3, baik dalam maupun luar negeri, dan biayanya di tanggung oleh pesantren.

c) Meningkatkan sarana dan prasarana pesantren seperti: menambah ruang laboratorium, menambah komputer, dan ruangan komputer, dlsb.

B. Kepada Ustadz dan Ustadzah agar lebih meningkatkan kinerja sehingga dapat mencapai hasil belajar yang optimal.

C. Kepada santriwan/santriwati:

a) Agar lebih meningkatkan aktivitas belajar sehingga dapat mencapai hasil belajar yang baik.

b) Agar dapat mencerminkan akhlakul karimah dalam kehidupan bermasyarakat.

c) Agar dapat berperan aktif di tengah-tengah mayarakat setelah lulus dari pesantren.

D. Kepada orang tua:

a) Agar lebih memperhatikan

kehidupan anak-anaknya yang belajar di pesantren dengan cara sering berkomunikasi kepada mereka.

b) Agar orang tua dapat meningkatkan kerja sama yang baik dengan para guru agar mencapai hasil belajar yang diinginkan.

E. Bagi peneliti selanjutnya:

a) Agar dapat menjadi bahan perbandingan bagi peneliti berikutnya khususnya yang tertarik meneliti tentang kurikulum pesantren. 
DAFTAR RUJUKAN

Andy. W, Dkk, 2012. MITRA Ar-

Raudhatul Hasanah, Medan:

Mitra Edisi 20.

Arno. Bellack/ Herbert, M Kliebard.

1977. Curriculum And

Evaluation.

Printed In The United States

Of America.

Arsyad, Azhar .2007. Media Pembelajaran, Jakarta: PT Raja Grafindo Persada.

Bungin, Burhan. 2008. Penelitian

Kualitatif. Jakarta: Kencana

Prenada Media Group.

David, Pratt 1980. Curriculum Design And Development. USA: Harcourt Brace Jovanovich, Publishers.

Imam, Zarkasyi 1996. Dari Gontor

Merintis Pesantren Modern.

Ponorogo: Gontor PRES.

Isjoni. 2009. KTSP Sebagai Pembelajaran Visioner.

Bandung: Alfabeta Cet 2.

Kafrawi. 1978. Pembaharuan Sistim

Pendidikan Pondok Pesantren,

Sebagai Usaha Peningkatan

Prestasi Kerja Dan Pembinaan

Kesatuan Bangsa. Jakarta: CV

Multiyasa \& CO.
Kumandar, 2007. Guru Professional Implementasi Kurikulum

Tingkat Satuan Pendidikan (KTSP) dan Satuan Sukses

Dalam Sertifikasi guru. Jagakarsa: Rajawali Press.

Lawrence, Stenhouse 1984. An Introduction to Curricurum Research and Development. London: Hernemann.

Rusman, 2012. Model- Model Pembelajaran. Bandung: Rajawali Press.

Sanjaya W, 2010. Perencanaan dan Desain Sistem Pembelajaran Jakarta: Kencana Prenada Media Group.

Skager R, and R. H. Dave, 1978. Curriculum Evaluation For Lifelong Education, Unesco Institute For Education: Pergamon Press.

Surya dkk, 2010. Landasan Pendidikan: Menjadi guru yang Baik. Bogor:

Ghalia Indonesia.

Yunus. 1973. Sejarah Pendidikan Islam Di Indonesia. Jakarta: Hidakarya

Agung. 
